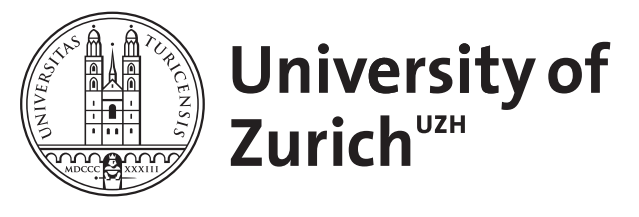

\title{
Antibiotic Algae by Chemical Surface Engineering
}

\author{
Kerschgens, Isabel P ; Gademann, Karl
}

\begin{abstract}
Chemical cell-surface engineering is a tool for modifying and altering cellular functions. Herein, we report the introduction of an antibiotic phenotype to the green alga Chlamydomonas reinhardtii by chemically modifying its cell surface. Flow cytometry and confocal microscopy studies demonstrated that a hybrid of the antibiotic vancomycin anda4-hydroxyproline oligomer binds reversibly to the cell wall without affecting the viability or motility of the cells. The modified cells were used to inhibit bacterial growth of Gram-positive Bacillus subtilis cultures. Delivery of the antibiotic from the microalgae to the bacterial cells was verified by microscopy. Our studies provide compelling evidence that 1) chemical surface engineering constitutes a useful tool for the introduction of new, previously unknown functionality, and 2) living microalgae can serve as new platforms for drug delivery.
\end{abstract}

DOI: https://doi.org/10.1002/cbic.201700553

Posted at the Zurich Open Repository and Archive, University of Zurich ZORA URL: https://doi.org/10.5167/uzh-150837

Journal Article

Accepted Version

Originally published at:

Kerschgens, Isabel P; Gademann, Karl (2018). Antibiotic Algae by Chemical Surface Engineering. Chembiochem, 19(5):439-443.

DOI: https://doi.org/10.1002/cbic.201700553 


\title{
Antibiotic Algae by Chemical Surface Engineering
}

\author{
Isabel P. Kerschgens and Karl Gademann*[a] \\ Dedication ((optional))
}

\begin{abstract}
Chemical cell surface engineering is a tool for modifying and altering cellular functions. Herein we report the introduction of an antibiotic phenotype to the green alga Chlamydomonas reinhardtii by chemically modifying its cell surface. Flow cytometry and confocal microscopy studies demonstrated that a hybrid of the antibiotic vancomycin and a 4-hydroxyproline oligomer binds reversibly to the cell wall without affecting the viability and motility of the cells. The modified cells were used to inhibit bacterial growth of Gram-positive Bacillus subtilis cultures. Delivery of the antibiotic form the microalgae to the bacterial cells is supported by microscopy. Our studies provide compelling evidence that (a) chemical surface engineering constitutes a useful tool for the introduction of new, previously unknown functionality, and that (b) living microalgae can serve as new platforms for drug delivery.
\end{abstract}

Over recent decades, cell surface engineering has emerged as a key technology for regulating cellular communication and at the same time altering fundamental functions. In particular, two main approaches to achieving this goal constitute genetic ${ }^{[1]}$ or metabolic surface engineering ${ }^{[2]}$ both using the biosynthetic machinery of the cell. In the first case, modification of the genetic code leads to the expression of a protein epitope on the cell surface (see Figure 1). On the other hand, metabolic engineering involves feeding the cells with modified monomers for cell surface biosynthesis that can be functionalized later using bio-orthogonal chemistry. ${ }^{[3]}$ Both techniques are permanent and in the case of genetic expression also hereditary. More recently, a chemical approach to this fundamental challenge has been developed using exogenous materials that interact with the outer parts of the cell surface allowing a more controlled, non-permanent and non-genetic manner to functionalize cell walls. ${ }^{[4]}$ These techniques involve the direct reaction of functional materials with amine or thiol groups on the cell surface ${ }^{[5]}$, hydrophobic materials inserting into cell membranes ${ }^{[6]}$, materials attached by electrostatic interactions, ${ }^{[7]}$ and others. ${ }^{[8]}$

Microalgae are multifunctional living materials that have been used in numerous applications such as $\mathrm{CO}_{2}$-fixation for production of biodiese[ ${ }^{[9]}$ and food ingredients, ${ }^{[10]}$ as well as oxygen producers in wound healing. ${ }^{[11]}$ However, their utilization

[a] Dr. I. Kerschgens, Prof. Dr. K. Gademann

Department of Chemistry

University of Zurich

Winterthurerstrasse 190

8057 Zurich

E-mail: karl.gademann@chem.uzh.ch

Supporting information for this article is given via a link at the end of the document. as drug delivery systems has been much less explored. Whereas biopolymers of microalgae have been recognized to be materials for drug delivery, ${ }^{[12]}$ the potential for entire, nongenetically modified, and living cells as agents for drug delivery has not yet been investigated to the best of our knowledge. The only examples published so far involve dead, genetically engineered diatom silica for the delivery of anti-cancer agents ${ }^{[13]}$ and genetically engineered green algae for the production of immunotoxin anticancer therapeutics. ${ }^{[14]}$ We therefore hypothesize whether living microalgae could be directly used for drug delivery applications employing chemical surface engineering instead of genetic engineering approaches.

In this study, we report the functionalization of the green alga Chlamydomonas reinhardtii using chemical surface engineering with an antibiotic hybrid. The resulting modified algae have been shown to kill Gram-positive bacteria, thereby delivering the antibiotic from the algae to the target pathogen.

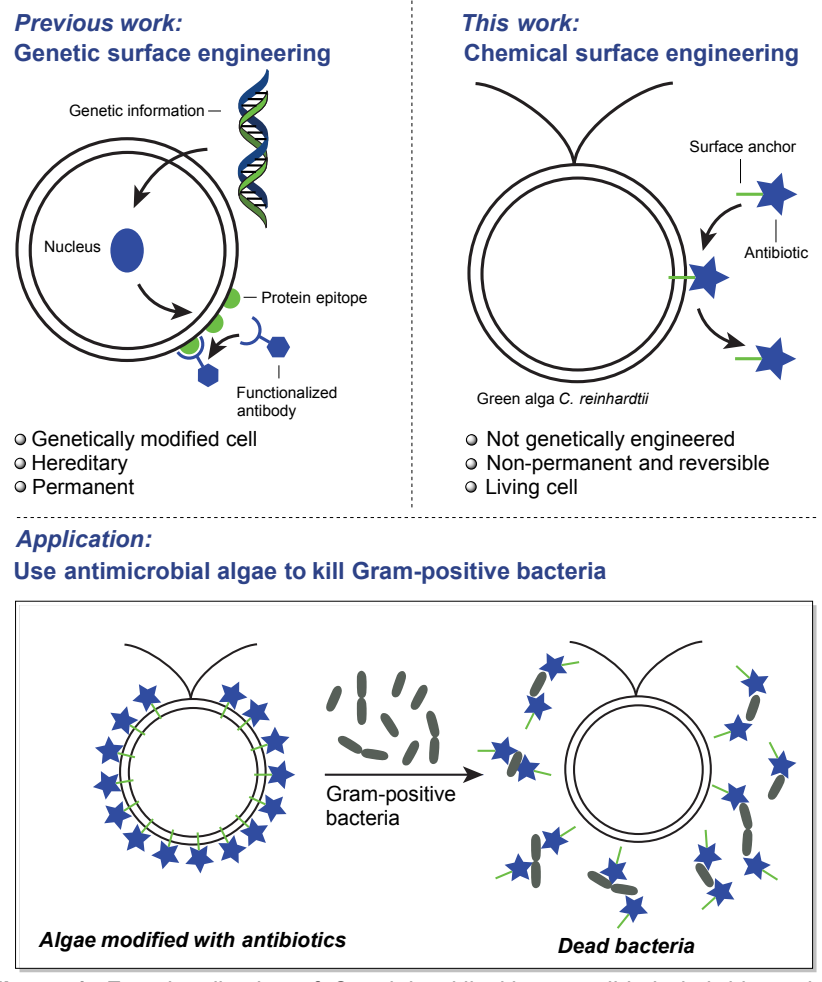

Figure 1: Functionalization of $C$. reinhardtii with an antibiotic hybrid can be used to fight Gram-positive bacteria.

The microalga $C$. reinhardtii serves as a model organism for the study of fundamental processes in biology. ${ }^{[15]}$ This eukaryotic unicellular phototroph comprises two flagella, which control motility via phototactic responses. ${ }^{[16]}$ In the past, it has therefore been utilized as a molecular motor to transport polymer beads through microfluidic channels. ${ }^{[17]}$ The beads were attached to the 
cell wall using a 4-hydroxyproline oligomer by non-covalent interactions with the glycopeptides of the cell wall of $C$. reinhardtii. For the functionalization of the algal cell wall, we envisioned a hybrid of the oligoproline anchor and an antibiotic. To this goal, we chose vancomycin, a glycopeptide highly active against Gram-positive bacteria, and which had previously been used successfully by us for the functionalization of $\mathrm{TiO}_{2}$ surfaces. ${ }^{[18]}$ Based on these design principles, we engineered the target vancomycin hybrid $\mathbf{1}$, which displays high water solubility and fluorescent properties (Figure 1). Its preparation involved a combination of solid-phase and solution-phase peptide synthesis techniques (see supporting information).

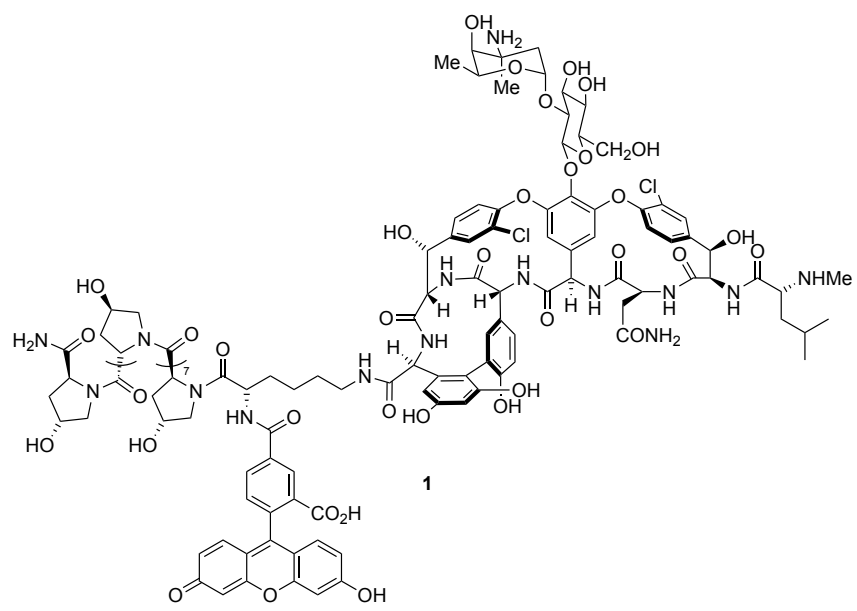

Figure 2: The target hybrid 1 connecting the antibiotic vancomycin with a oligohydroxyproline anchor containing a fluorophore for in vivo cell imaging.

First, we investigated the attachment of hybrid 1 to the surface of $C$. reinhardtii. Algae cells were incubated in a solution of 1 (1 $\mu \mathrm{mol} / \mathrm{mL}$ ) in algae medium for $12 \mathrm{~h}$. The cells were washed and inspected with a confocal fluorescent microscope. As hypothesized, compound $\mathbf{1}$ adhered strongly to the algal cells in the presence of excess of 1 . We observed attachment of the compound primarily to the surface but we also detected internalization of the hybrid (Figure 3f). Attachment of the compound 1 and viability of the cells were strongly dependent on the incubation time and concentration. High concentrations of construct $1(4.5 \mu \mathrm{mol} / \mathrm{mL})$ led to immediate disruption of motility and resulted in strong internalization of substance. However, when concentration, incubation time and cell density were carefully optimized, viability and motility of the cells were fully maintained. ${ }^{[19]}$ As evidence for the successful attachment of vancomycin derivative 1 with retained cell viability, we performed flow cytometry measurements with untreated and modified cells. The cells were analyzed by detection of fluorescein for the presence of fluorescently labelled 1 and the cells were subjected to propidium iodide prior to the flow cytometry measurement. Propidium iodide is a nuclei-staining dye and penetrates only through disrupted areas of cell walls thereby labelling only dead cells. ${ }^{[20]}$ While untreated cells acting as a negative control did not reveal any green fluorescence (Figure 3c), these cultures contained a minor amount of dead cells $(\approx 13 \%)$ that were propidium iodide positive (Figure $3 \mathrm{~d}$ ) and are plotted together with a control sample of entirely dead cells ${ }^{[21]}$ (blue curve). Algae that have been modified with 1 significantly enhanced fluorescence (Figure $3 \mathrm{~g}$ ). The smaller population that was labelled more intensely than the main population were mostly attributed to the dead cells, ${ }^{[22]}$ an effect that is also observed in immunofluorescence. The number of propidium iodide positive cells $(\approx 12 \%)$ did not increase compared to the control of unmodified cells (Figure $3 \mathrm{~h}$ ). These results are consistent with the previously assessed motility of the cells. We observed that incubation of the cells with 4-hydroxyproline oligomers without vancomycin (with and without fluorescent label) resulted in cell death, an effect that contradicts other cell penetrating cationic oligoprolines ${ }^{[23]}$ and needs to be further investigated. We also observed that the binding of $\mathbf{1}$ to the algae cells is reversible and allowing the modified cells to stand for 2 days resulted in nearly complete release of the compound from the living cells (supplementary information Figure S7). We hypothesize that the reversible nature of binding is necessary for the delivery of 1 to the surface of the bacteria and represents a rare example of reversible chemical surface engineering. ${ }^{[24]}$ As a control experiment we also attempted the attachment of fluorescently labeled vancomycin derivatives ${ }^{[25]}$ using BODIPY and fluorescein as fluorophores, however, these experiments were challenging because of the drastically reduced water solubility of these compounds under the incubation conditions.
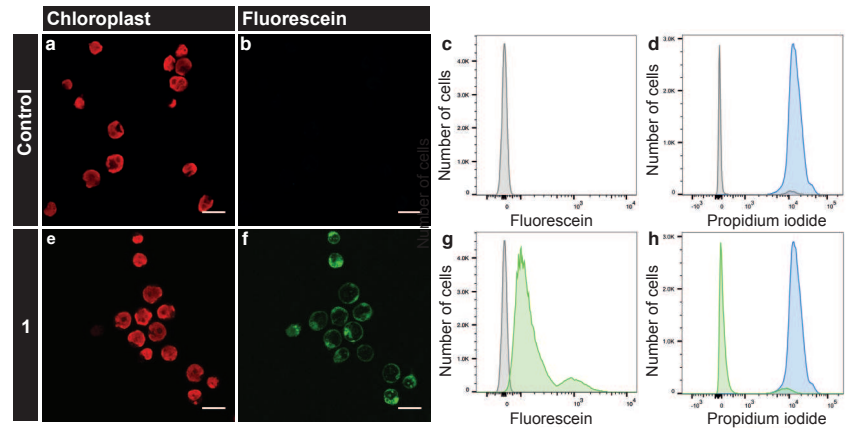

Figure 3: Confocal fluorescence microscopy images and flow cytometry of $C$. reinhardtii after incubation with 1 at a concentration of $1 \mu \mathrm{mol} / \mathrm{mL}$ for $12 \mathrm{~h}$. a Chloroplast of untreated $C$. reinhardtii. b, No fluorescein fluorescence is obtained for untreated C. reinhardtii c, Flow cytometry histogram of untreated cells showing no fluorescein fluorescence. d, Flow cytometry histogram of untreated cells showing small amounts of dead cells (grey) against a control of dead cells (blue). e, Autofluorescence of $C$. reinhardtii incubated with 1. f, Modified cells showed primary localization of 1 on the surface of the algae but partly also internalized in the cells. g, Flow cytometry shows quantitative modification $C$. reinhardtii. $\mathbf{h}$, Propidium iodide staining revealed that modification with 1 did not result in higher cell death than in the control samle.

We next evaluated if the modified algal cells carrying the vancomycin hybrid 1 were able to kill bacteria. To this goal, the effect of the hydroxyproline anchor on the antimicrobial potency of vancomycin was examined first. Disk diffusion and MIC assays indicated a decrease in activity of hybrid 1 compared to vancomycin $(\sim 30 \mathrm{x})$. Reduced activity is likely due to the decreased binding ability because of the attached oligoproline anchor of $\mathbf{1}$ to the $\mathrm{N}$-acyl-D-Ala-D-Ala fragment of the target 
bacterial cell wall. ${ }^{[26]}$ However, the MIC value of $4-8 \mu \mathrm{g} / \mathrm{mL}$ demonstrated in general retained activity. We therefore proceeded to subjected $C$. reinhardtii modified with construct 1 to growing cultures of $B$. subtilis. Growth of bacteria was monitored by the UV-absorption of the cultures at $600 \mathrm{~nm}$ $\left(\mathrm{OD}_{600}\right)^{[27]}$ In addition to $C$. reinhardtii that was previously incubated with 1 , we also monitored bacterial growth in the presence of unmodified algae (positive control) and algae that have previously been incubated with vancomycin (Figure 4). For lower algae culture densities (Figure $4 \mathrm{a}, 1.5 \cdot 10^{6} \mathrm{cells} / \mathrm{mL}$ ) we observed a slight inhibition of bacterial growth in the presence of modified algae (red) but no inhibition for algae previously incubated with vancomycin (grey). When we used more dense cultures of $C$. reinhardtii (Figure $4 \mathrm{~b}, 2.5 \cdot 10^{6}$ cells $/ \mathrm{mL}$ ) we could fully inhibit bacterial growth. We also observed a slight inhibition in the control of with vancomycin-incubated algae probably resulting from some vancomycin physically adsorbed on the surface of $C$. reinhardtii. However, considering the higher antimicrobial potency of vancomycin the amount of vancomycin actually adsorbed on the surface is presumably very low in comparison to the amount of surface-bound 1.
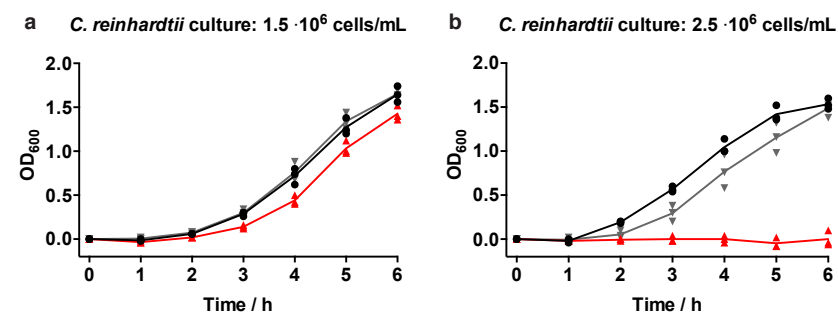

Figure 4: Bacterial growth in the presence of unmodified algae (-•-), algae that have previously been incubated with $\mathbf{1}(-\boldsymbol{\Delta}-)$ and algae previously been incubated with vancomycin $(-\nabla-) .6 \mathrm{~mL}$ of algae culture was used having a density of a, $1.5 \cdot 10^{6}$ cells $/ \mathrm{mL}$ and $\mathbf{b}, 2.5 \cdot 10^{6}$ cells $/ \mathrm{mL}$.

We wanted to corroborate these growth experiments by directly visualizing live and dead cells using fluorescence microscopy. Thus, fluorescent staining of the bacterial cultures shown in Figure $5 \mathrm{~b}$ was performed with fluorescent dyes after $6 \mathrm{~h}$ of incubation in the presence of algae (Figure 5). The twocomponent stain allows differentiation between living and dead cells by showing the living cells as green and dead cells as red fluorescent. Viable bacteria were stained by hydrolysis of the cell permeable calcein-AM to calcein that emits the same green fluorescence as fluorescein. Dead bacteria were stained with propidium iodide that emitted red fluorescence. The stained cultures were inspected using a confocal fluorescent microscope. For the bacteria grown in the presence of unmodified algae we observed a mixture of living and dead cells (Figure $5 a-c$ ). This can be explained by the fact that bacterial growth had already entered stationary phase and some dead cells were present. Importantly, the cells either emitted green or red fluorescence indicated by the merged image of the red and green channel. The bacteria exposed to modified algae showed a matched overlay of red and green (Figure $5 \mathrm{~d}-\mathrm{f}$ ). The cells present in the sample were all propidium iodide positive, which provides strong evidence for dead cells. At the same time, bacteria also exhibited green fluorescence, which we trace back to the fluorescently labeled hybrid 1 , that was delivered from the modified algae cells to the bacteria. When inspecting a magnified single layer image of this sample (Figure $5 \mathrm{~g}-\mathrm{i}$ ) the distribution of 1 on the bacteria shows that the hybrid primarily binds to the cell wall of the bacteria, which is consistent with the mode of action of vancomycin. Direct evidence for the stability of hybrid 1 during incubation of algae cells and later exposure to $B$. subtilis cultures is not obtained but our experiments show that vancomycin is still fluorescently labeled and we presume that 1 is still intact.

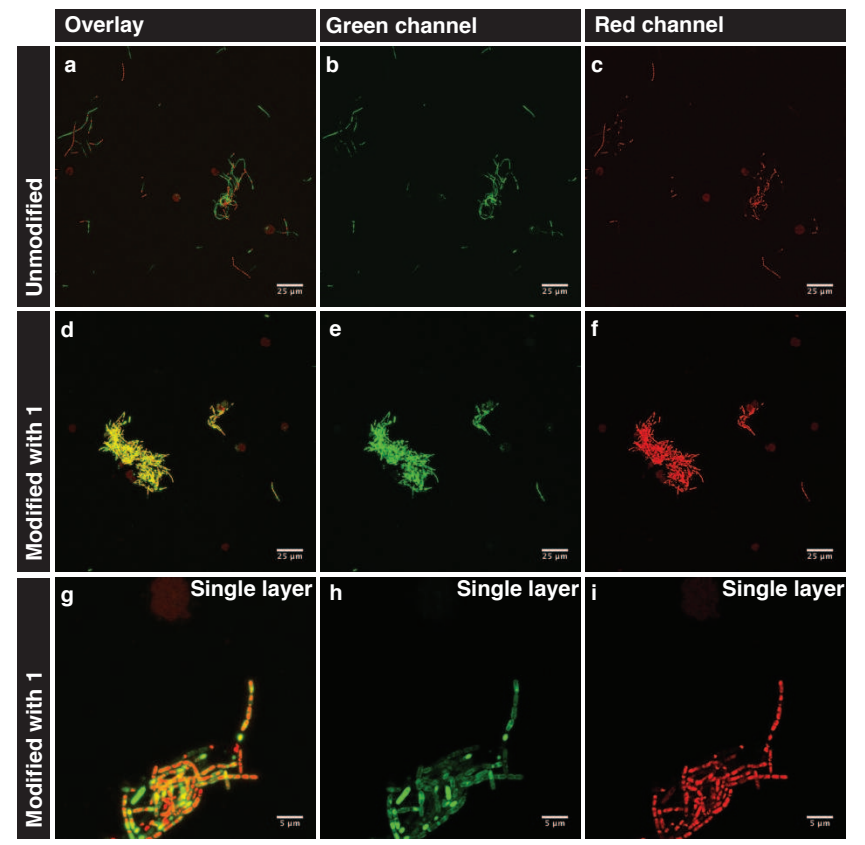

Figure 5: Staining of bacterial cultures after 6 hours with a live/dead kit. a-c Bacteria grown in the presence of unmodified algae. d-f, Bacteria grown in the presence of algae previously modified with $\mathbf{1}$. $\mathbf{g}-\mathbf{i}$, Magnified and single layer image of bacteria grown in the presence of algae previously modified with 1 .

Investigations into the mechanism of delivery revealed that hybrid $\mathbf{1}$ is able to partially dissociate from the cell wall of the algae into the medium within 1 hour (see supporting information Figure S15). This suggests that bacteria and algae do not necessarily need physical contact for delivery of 1 but that 1 can also be transferred by diffusion.

In order to test if hybrid $\mathbf{1}$ binds to the glycopeptides of the algal cell wall, we performed incubation experiments with a cell walldeficient mutant (supporting information Figure S16). We observed significantly less attachment of compound to the cell wall-deficient mutant than for the control experiment with the wild type. These data suggest that binding of 1 to $C$. reinhardtii is likely due to the non-covalent interaction with the glycopeptides present in the cell wall.

In summary, we have shown that chemical surface engineering can be utilized to reversibly functionalize the cell wall of living algae. We demonstrated the transformation of microalgae into killer cells for Gram-positive bacteria by attachment of an 
antibiotic to the cell surface of the algae. Binding of the natural product hybrid to the algae cells is reversible and the noncovalent interaction is suggested to take place with the glycopeptides present in the cell wall. The viable, modified cells were able to deliver the antibiotic to the bacteria and resulted in complete inhibition of bacterial growth. Our work opens intriguing prospects for further functionalization and utilization of microalgae in chemical biology, and potentially, human medicine For further and in-depth evaluation in a therapeutic setting, studies are required targeting potential challenges such as the immune response against the amount of algae.

\section{Acknowledgements}

We acknowledge the Center for Microscopy and Image Analysis (ZMB) and the Flow Cytometry Facility of the University of Zurich for training and maintenance of the instruments. Miriam Gwerder is kindly acknowledged for MIC value determination and Dr. Nadine Bohni and Simone Grendelmeier for flow cytometry parameters. Prof. Dr. Severin Sasso and Dr. Katja Zerbe are kindly acknowledged for scientific discussions. We thank the Swiss National Science Foundation for financial support (200020_163151).

\section{Conflict of interest}

The authors declare no conflict of interest.

Keywords: chemical surface engineering $\bullet$ microalgae $•$ vancomycin • natural product hybrid

[1] M. M. Stevens, J. H. George, Science 2005, 310, 1135-1138

[2] L. K. Mahal, C. R. Bertozzi, Chemistry \& Biology 1997, 4, 415-422.

[3] a) L. K. Mahal, K. J. Yarema, C. R. Bertozzi, Science 1997, 276, 1125 1128. b) E. Saxon, C. R. Bertozzi, Science 2000, 287, 2007-2010. c) J. A. Prescher, D. H. Dube, C. R. Bertozzi, Nature 2004, 430, 873-877.

[4] For a review see: M. T. Stephan, D. J. Irvine, Nano Today 2011, 6, 309-325.

[5] a) M. T. Stephan, J. J. Moon, S. H. Um, A. Bershteyn, D. J. Irvine, Nat. Med. 2010, 16, 1035-1042. b) S. C. Hsiao, B. J. Shum, H. Onoe, E. S. Douglas, Z. J. Gartner, R. A. Mathies, C. R. Bertozzi, M. B. Francis Langmuir 2009, 25, 6985-6991. c) D. Sarkar, P. K. Vemula, G. S. L. Teo, D. Spelke, R. Karnik, L. Y. Wee, J. M. Karp, Bioconjugate Chem 2008, 19, 2105-2109. d) D. Y. Lee, S. J. Park, J. H. Nam, Y. Byun, Tissue Eng. 2006, 12, 615-623.

[6] a) I. K. Ko, T. J. Kean, J. E. Dennis, Biomaterials 2009, 30, 3702-3710. b) D. Rabuka, M. B. Forstner, J. T. Groves, C. R. Bertozzi, J. Am. Chem. Soc. 2008, 130, 5947-5953. c) A. Chen, G. Zheng, M. L. Tykocinski, J. Immunol. 2000, 164, 705-711.

[7] a) J. T. Wilson, V. R. Krishnamurthy, W. Cui, Z. Qu, E. L. Chaikof, J. Am. Chem. Soc. 2009, 131, 18228-18229. b) S. Hong, P. R. Leroueil, E. K. Janus, J. L. Peters, M.-M. Kober, M. T. Islam, B. G. Orr, J. R. Baker Jr., M. M. Banaszak Holl, Bioconj. Chem. 2006, 17, 728-734.
[8] a) M. G. Paulick, C. R. Bertozzi, Biochemistry 2008, 47, 6991-7000. b) A. J. Swiston, C. Cheng, S. H. Um, D. J. Irvine, R. E. Cohen, M. F. Rubner, Nano Lett. 2008, 8, 4446-4453. c) X. Chen, U. C. Tam, J. L. Czlapinski, G. S. Lee, D. Rabuka, A. Zettl, C. R. Bertozzi, J. Am. Chem. Soc. 2006, 128, 6292-6293.

[9] For reviews see: a) T. M. Mata, A. A. Martins, N. S. Caetano Renewable Sustainable Energy Rev. 2010, 14, 217-232. b) B. Zhao, Y Su, Renewable Sustainable Energy Rev. 2014, 31, 121-132.

[10] M. Herrero, A. Cifuentes, E. Ibanez, Food Chem. 2006, 98, 136-148.

[11] a) T. L. Schenck, U. Hopfner, M. N. Chávez, H.-G. Machens, I. SomlaiSchweiger, R. E. Giunta, A. V. Bohne, J. Nickelsen, M. L. Allende, J. T. Egaña, Acta Biomaterialia 2015, 15, 39-47. b) M. N. Chávez, T. L. Schenck, U. Hopfner, C. Centeno-Cerdas, I. Somlai-Schweiger, C. Schwarz, H.-G. Machens, M. Heikenwalder, M. R. Bono, M. L. Allende, J. Nickelsen, J. T. Egaña, Biomaterials 2016, 75, 25-36.

[12] For reviews see: a) T. H. Silva, A. Alves, E. G. Popa, L. L. Reys, M. E. Gomes, R. A. Sousa, S. S. Silva, J. F. Mano, R. L. Reis, Biomatter 2014, 2, 278-289. b) C. E. Beneke, A. M. Viljoen, J. H. Hamman, Molecules 2009, 14, 2602-2620. c) J. H. Hamman, Marine Drugs 2010 8, 1305-1322. d) N. K. Sachan, S. Pushkar, A. Bhattcharya, J. Pharm. Res. 2009, 2, 1191-1199.

[13] B. Delalat, V. C. Sheppard, S. R. Ghaemi, S. Rao, C. A. Prestidge, G McPhee, M.-L. Rogers, J. F. Donoghue, V. Pillay, T. G. Johns, N. Kröger, N. H. Voelcker, Nat. Commun. 2015, 6, 1-11.

[14] M. Tran, C. Van, D. J. Barrera, P. L. Pettersson, C. D. Peinado, J. Bui, S. P. Mayfield, Proc. Natl. Acad. Sci. U.S.A. 2013, 110, E15-22.

[15] E. H. Harris, Annu. Rev. Plant Physiol. Plant Mol. Biol. 2001, 52, 363406.

[16] R. L. Stavis, R. Hirschberg J. Cell Biol. 1973, 59, 367-377.

[17] D. B. Weibel, P. Garstecki, D. Ryan, W. R. DiLuzio, M. Mayer, J. E. Seto, G. M. Whitesides, Proc. Natl. Acad. Sci. U.S.A. 2005, 102, 11963-11967.

[18] J.-Y. Wach, S. Bonazzi, K. Gademann, Angew. Chem. Int. Ed. 2008, 47, 7123-7126.

[19] We also determined the amount of 1 attached to a suspension of algae by UV spectroscopy. For cell suspensions with $1.5 \cdot 10^{6}$ cells $/ \mathrm{mL}$ we obtained a loading of $\approx 10-20 \mu \mathrm{g} / \mathrm{mL}$ (see supporting information). This corresponds to $13.6 \cdot 10^{8}-27.2 \cdot 10^{8}$ molecules of hybrid 1 per alga cell.

[20] H. M. Davey, Appl. Environ. Microbiol. 2011, 77, 5571-5576.

[21] The control sample of dead cells was prepared by heating a cell sample to $90^{\circ} \mathrm{C}$ for $15 \mathrm{~min}$.

[22] This correlation can be seen in the 2D-plot provided in the experimental part (Figure S6)

[23] a) Y. A. Fillon, J. P. Anderson, J. Chmielewski, J. Am. Chem. Soc. 2005, 127, 11798-11803. b) L. Li, I. Geisler, J. Chmielewski, J.-X. Cheng, J. Controlled Release 2010, 142, 259-266. c) A. A. Brezden, M. F. Mohamed, M. Nepal, J. S. Harwood, J. Kuriakose, M. N. Seleem, J. Chmielewski, J. Am. Chem. Soc. 2016, 138, 10945-10949. d) B. Kolesinska, D. J. Podwysocka, M. A. Rueping, D. Seebach, F. Kamena, P. Walde, M. Sauer, B. Windschiegl, M. Meyer-Ács, M. Vor der Brüggen, et al., Chem. Biodiversity 2013, 10,1-38.e) Y. A. Nagel, P. S Raschle, H. Wennemers, Angew. Chem. Int. Ed. 2017, 56, 122-126.

[24] S. H. Yang, J. Choi, L. Palanikumar, E. S. Choi, J. Lee, J. Kim, I. S. Choi, J.-H. Ryu, Chem. Sci. 2015, 6, 4698-4703. 
[25] a) D. A. MacKenzie, A. R. Sherratt, M. Chigrinova, A. J. Kell, J. P.

Pezacki Chem. Commun., 2015, 51, 12501-12504. b) M. S. Siegrist, S.

Whiteside, J. C. Jewett, A. Aditham, F. Cava, C. R. Bertozzi

ACS Chem. Biol. 2013, 8, 500-505

[26] a) M. Nieto, H. R. Perkins Biochem. J. 1971, 123, 789-803. b) H. R. Perkins Pharmac. Ther. 1982, 16, 181-197.

[27] a) J. A. Myers, B. S. Curtis, W. R. Curtis, BMC Biophysics 2013, 6, 116. b) W. A. Velema, J. P. van der Berg, M. J. Hansen, W. Szymanski, A. J. M. Driessen, Ben L. Feringa, Nat. Chem. 2013, 924-928. 


\section{COMMUNICATION}

Killer cell: Living microalgae have been modified by chemical surface engineered. The organisms can be coated with an antibiotic-hybrid to kill Gram-positive bacteria. The antibiotic is transferred from the algae to the bacteria thereby opening new prospects for applications of microalgae in drug delivery.

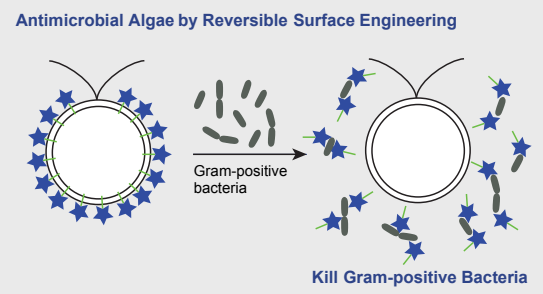

Isabel P. Kerschgens, Karl

Gademann*

Page No. - Page No.

Antibiotic Algae by Chemical Surface Engineering 